\title{
TENDÊNCIAS DO ENSINO DE LITERATURA NO LIVRO DIDÁTICO DO ENSINO MÉDIO
}

\author{
LITERATURE TEACHING TENDENCIES IN THE HIGH \\ SCHOOL TEXTBOOK
}

\section{TENDENCIAS DE LA ENSEÑANZA DE LITERATURA EN EL LIBRO DIDÁCTICO DE LA ENSEÑNANA SECUNDARIA}

\author{
Giovana Tavernari Payão ${ }^{1}$ \\ https://orcid.org/0000-0002-7902-1060 \\ Sérgio Fabiano Annibal ${ }^{2}$ \\ https://orcid.org/0000-0001-5935-7854
}

\footnotetext{
${ }^{1}$ Universidade Estadual Paulista, Marília, São Paulo - Brasil. E-mail: giovana.tavernari@ gmail.com.

${ }^{2}$ Universidade Estadual Paulista, Marília, São Paulo - Brasil. E-mail: sergioannibal@gmail.com.
}

\section{Resumo}

O presente artigo tem como objetivo apresentar os resultados de uma pesquisa sobre representações literárias e seus desdobramentos em comandas de ensino nos livros didáticos Novas Palavras (AMARAL, 2013) e Português: Linguagens (CEREJA, MAGALHÃES, 2013), do Programa Nacional do Livro Didático (PNLD), referentes ao primeiro ano do Ensino Médio, durante o triênio 2015-2017. Durante a investigação, pautada em análise documental, os textos literários na íntegra, os excertos literários e as comandas para o ensino de literatura desses livros foram catalogados e organizados, a fim de se estabelecerem as tendências pedagógicas e literárias do ensino de literatura. Foram considerados também os gêneros literários, textuais e discursivos presentes no corpus, bem como os descritores/impulsionadores de ação das comandas para o ensino de literatura nesses livros didáticos. A partir da análise realizada, percebe-se, ainda, a presença da tendência pedagógica liberal tecnicista e da abordagem tradicional, bem como um viés estruturalista do conteúdo literário.

Palavras-chave: Formação de Professores. Livro Didático. Ensino de Literatura. Tendências Pedagógicas.

\section{Abstract}

The aim of this article is to present the results of a research about literary representations and its teaching proposals in the textbooks Novas Palavras (AMARAL, 2013) and Português: Linguagens (CEREJA, MAGALHÃES, 2013), referring to the first year of High School, in the three-year term 2015-2017. During the investigation, based on documental analysis, the full 
literary texts, the literary excerpts and the exercises of literature teaching of these books were separated and organized, in order to establish the pedagogical and literary tendencies of literature teaching. There were also considered the literary, textual and discursive genres existing on the corpus, as well as the descriptors/drivers of action presented on the exercises of literature teaching in these textbooks. From the analysis, it is possible to understand, still, the presence of the liberal technicist pedagogical tendency and the traditional approach, as well as an structuralist literary slant of the literary content.

Keywords: Teacher's Education. Textbook. Literature Teaching. Pedagogical Tendencies.

\section{Resumen}

El presente artículo tiene como objetivo presentar los resultados de una investigación sobre representaciones literarias y sus desenvolvimientos en las comandas de enseñanza en los libros didácticos Novas Palavras (AMARAL, 2013) y Português: Linguagens (CEREJA, MAGALHÃES, 2013), referentes al primer año de la Enseñanza Secundaria, en el trienio 2015 2017. Durante la investigación, regida por el análisis documental, los textos literarios, los breves resúmenes literarios y las comandas para la enseñanza de la literatura han sido propuestos y organizados, asi que ha sido posible establecer las tendencias pedagógicas y literarias de la enseñanza de literatura. Fueron catalogados también los géneros literarios, textuales y discursivos que se encontraban en el corpus, y también los descriptores/impulsores de acción de las comandas para la enseñanza en los libros didácticos. Desde el análisis realizada, se percibe, todavía, la presencia de la tendencia pedagógica liberal técnico y del abordaje tradicional, como también una inclinación estructural del contenido literario.

Palabras clave: Formación de Profesores. Libro Didáctico. Enseñanza de Literatura. Tendencias Pedagógicas.

\section{A literatura e o ensino}

O presente artigo decorre dos resultados de investigação financiada pela Fundação de Amparo à Pesquisa do Estado de São Paulo (FAPESP), processo nº 2017/10746-0. O ensino de literatura tem sido discutido tanto no campo das Letras como no da Educação e, nesse sentido, a primeira problemática que se deve considerar é a definição do que é literatura:

[...] todas as criações de toque poético, ficcional ou dramático em todos os tipos de cultura, desde o que chamamos folclore, lenda, chiste, até as formas mais complexas e difíceis da produção escrita das grandes civilizações. (CANDIDO, 1988, p. 176.)

Desse modo, o autor conceitua a literatura como algo intrínseco ao homem e seu papel no mundo, ressaltando que o ser humano tem necessidade de efabulação. A literatura, assim, humaniza e é responsável por uma fuga para o consciente e o inconsciente. Além disso, pode 
constituir um caminho de instrução e educação, transmitindo valores e despertando provocações, de forma que pode fazer que seus leitores pensem e questionem o tempo e o espaço que os cerca.

Neste artigo, a questão que envolve o ensino de literatura é o centro da discussão. No Ensino Médio, o texto literário pode ser apresentado na íntegra ou fragmentado e ter a história da literatura como perspectiva dominante.

Assinala-se, a partir dos estudos sobre o ensino de literatura, o que inclui o livro didático (LD), que a expressão "leitura literária”, cada vez mais utilizada nessa discussão, ganha espaço privilegiado em relação à ideia de ensino. Dessa forma, nota-se, por meio dessa utilização lexical, uma mudança no sentido pedagógico, uma vez que, no primeiro (ensino), a atenção concentra-se no professor e, no segundo (leitura literária-leitor), volta-se para o aluno (REZENDE, 2013, p. 106).

Esse deslocamento é crucial, pois a retirada do foco de quem ensina para lançá-lo a quem aprende implica uma mudança de paradigma, podendo não deixar suficientemente claro o papel do professor no que diz respeito ao ensino da literatura.

Ressalta-se, segundo Dalvi (2011), que é imprescindível compreender o valor do livro didático como objeto de estudo e de acesso ao conhecimento literário:

[...] trabalhar com o ensino de leitura e literatura (portanto, com a formação de leitores) no período contemporâneo no Brasil requer considerar: a) de um lado, a enorme quantidade de fontes e objetos de estudo possíveis, bem como a consequente variedade de práticas de leitura para que sinalizam; e b) de outro lado, considerar que os livros didáticos têm inegável importância na economia da edição e na organização das práticas de leitura levadas a turno pelo processo de escolarização formal (p. 31).

Em consonância com o que Dalvi assinalou no item $b$, considerar a relevância do livro didático como objeto cultural de mediação entre o texto literário e sua didatização é fundamental para esta discussão. Sendo assim, as reflexões sobre o ensino de literatura trazidas para este artigo se dão a partir de duas obras didáticas pertencentes às coleções Novas Palavras (AMARAL, 2013) e Português: Linguagens (CEREJA; MAGALHÃES, 2013), ambas do triênio 2015-2017 do Plano Nacional do Livro Didático (PNLD), referentes ao primeiro ano do Ensino Médio. 
A análise desses documentos didáticos se deu mediante o levantamento e a organização do conteúdo literário presente nesses volumes e das comandas de ensino que o acompanham. Foi possível identificar tendências, tanto pedagógicas como literárias, que estão presentes no ensino de literatura representado pelos livros didáticos.

\section{0 corpus e a abordagem teórica}

A escolha desses Livros didáticos se justifica pelos seguintes fatos: 1. inseriam-se no PNLD, triênio 2015-2017; 2. foram utilizados, nesse período em escolas da rede estadual paulista. A pesquisa realizada sobre o ensino de literatura em livros didáticos teve caráter qualitativo, com utilização exclusiva de análise documental, e foi amparada metodologicamente em Lüdke e André (2005).

A coleção Novas Palavras (AMARAL, 2013) possui três volumes, cada um referente a um ano do Ensino Médio, os quais se encontram divididos em três partes, sendo elas: "Literatura", "Gramática" e "Redação e Leitura".

No que se refere, especificamente, à literatura, estabelece-se uma ordem cronológica: explicação e contextualização do que é literatura e história da literatura por meio das escolas literárias, frequentemente divididas entre portuguesa e brasileira. O LD contém atividades que preveem uma primeira leitura literária e, posteriormente, comandas que visam a esmiuçar ou aprofundar a leitura em seções intituladas "Releitura". Vê-se, assim, uma disposição da leitura em camadas, ora mais superficiais e de apresentação, ora mais verticalizadas. Além disso, há tentativas de fomentar o debate acerca do texto literário, como se observa nas seções de "Discussão" e "Em tom de conversa". Desse modo, o LD do primeiro ano do Ensino Médio divide-se em 10 capítulos: 
Quadro 1 - Capítulos do livro Novas Palavras (2013).

\begin{tabular}{|l|}
\hline 1. Literatura: a arte da palavra \\
\hline 2. O texto literário \\
\hline 3. O Trovadorismo \\
\hline 4. O Humanismo \\
\hline 5. O Renascimento \\
\hline 6. O Quinhentismo brasileiro \\
\hline 7. O Barroco português \\
\hline 8. O Barroco brasileiro \\
\hline 9. O Neoclassicismo português \\
\hline 10. O Neoclassicismo brasileiro \\
\hline
\end{tabular}

Fonte: AMARAL, 2013.

Da mesma forma que Novas Palavras (2013), a coleção Português: Linguagens (CEREJA; MAGALHÃES, 2013) possui três volumes, um para cada ano do Ensino Médio, e busca abordar competências da leitura, da literatura, da produção escrita e dos conhecimentos linguísticos, sendo cada LD dividido em quatro unidades. A organização se dá por meio de escolas literárias, baseando-se na periodização das literaturas portuguesa e brasileira.

Português: Linguagens (2013) conta com agrupamentos de três ou quatro ocorrências literárias, distribuídas ao longo dos capítulos. Geralmente, trata-se de traduções e adaptações feitas pelos autores da coleção e, para cada agrupamento de texto literário na íntegra ou excertos, encontram-se comandas para o ensino de literatura.

Outro aspecto a se destacar nessa obra didática é que, em quase todos os capítulos, existe uma seção chamada "Leitura complementar", em que os autores disponibilizam referências não literárias com o objetivo de estabelecer relação com o conteúdo literário, como textos teóricos, filmes e websites. Isso, por sua vez, reforça a abordagem que privilegia uma história da literatura com o auxílio de elementos que não estão inseridos nela.

No sentido de evidenciar a estruturação desse LD, apresentam-se tópicos/tema do volume dedicado ao primeiro ano do Ensino Médio nos quais se observam uma definição de literatura e uma sequência de escolas literárias: 
Quadro 2 - Capítulos do livro Português: Linguagens (2013).

\begin{tabular}{|l|}
\hline 1. O que é literatura? (U. 1, C. 1) \\
\hline 2. A linguagem do Trovadorismo (U. 1, C. 5) \\
\hline 3. A produção literária medieval (U. 1, C. 8) \\
\hline 4. A linguagem do Classicismo renascentista (U 2, C. 1) \\
\hline 5. O Classicismo em Portugal (U. 2, C. 4) \\
\hline 6. O Quinhentismo no Brasil (U. 2, C. 7) \\
\hline 7. A linguagem do Barroco (U. 3, C. 1) \\
\hline 8. O Barroco em Portugal (U. 3, C. 4) \\
\hline 9. O Barroco no Brasil (U. 3, C. 7) \\
\hline 10. A linguagem do Arcadismo (U. 4, C. 1) \\
\hline 11. O Arcadismo em Portugal (U. 4, C. 4) \\
\hline 12. O Arcadismo no Brasil (U. 4, C. 7) \\
\hline
\end{tabular}

Fonte: CEREJA; MAGALHÃES, 2013.

Quanto às tendências pedagógicas, seguiram-se as denominações empregadas por Libâneo, em sua obra Democratização da Escola Pública (1985), e Mizukami, em Ensino: as abordagens do processo (1986). Embora se trate de obras situadas nos anos 1980, são fundamentais para organizar e refletir modelos e formas de ensino a partir de concepções de ensino e de correntes pedagógicas em conjunturas econômicas, sociais e políticas específicas.

Quanto às tendências literárias, contam-se com as contribuições teóricas de Eagleton, em Teoria da Literatura (2006), e de autores que dedicaram suas obras à teoria e à crítica literária e à elaboração de manuais de literaturas brasileira e portuguesa, a saber: Bandeira (1960), Bosi (1972), Campato Jr. (2016), Dantas (1979), Pires (1981) e Soares Amora (1970). O levantamento e a comparação dos manuais de literatura foram importantes para situar o corpus da pesquisa, os livros Novas Palavras (2013) e Português: Linguagens (2013), no sentido de possibilitar mais compreensão de como, historicamente, vem se pensando esse ensino, ou seja, divisões didáticas em escolas literárias, utilização de recortes de textos literários por meio de excertos, contextualização histórica do autor e, por vezes, relação desses dados históricos com a obra literária. 


\section{As propostas de ensino nos livros didáticos}

Realizaram-se levantamentos e organização do conteúdo literário presente nos livros didáticos e, para isso, elaborou-se um quadro contendo a coleção indicada, o capítulo/página, o gênero literário, a referência bibliográfica, o texto literário e, na maioria das vezes as ocorrências de comandas de ensino de literatura.

Esclarece-se que optou-se pela categorização das ocorrências literárias e propostas de ensino de Literatura, a saber: "excertos literários" são entendidos de maneira estrita e dicionarizada, ou seja, fragmento ou parte extraída de obra literária e presente no LD; propostas de ensino são aqui nomeadas como "comandas para o ensino de Literatura", partindo, assim, do verbo comandar ou indicar o que o outro, no caso o estudante, deve fazer; e o item "textos literários na íntegra" é empregado para indicar que o texto presente nos livros didáticos não teve trechos ou partes suprimidas.

Eis um exemplo:

Quadro 3 - Exemplo de "Texto literário na íntegra" e "Comandas para o ensino de Literatura" da coleção Novas Palavras (2013).

Coleção: Novas Palavras

Capítulo 2, página 38

Poesia

Ao Conde de Ericeira D. Luiz de Menezes pedindo louvores ao poeta, não lhe achando ele préstimo algum. Gregório de Matos. Obra Poética. Edição de James Amado; preparação e notas de Emanuel Araújo. 3. Ed. Rio de Janeiro.: Record, 1992. V. 1, p. 129.

Um soneto começo em vosso gabo;

Contemos esta regra por primeira,

Já lá vão duas, e esta é a terceira,

Já este quartetinho está no cabo.

Na quinta torce agora a porca o rabo:

A sexta vá também desta maneira,

Na sétima entro já com grã canseira,

E saio dos quartetos muito brabo.

Agora nos tercetos que direi?

Direi, que vós, Senhor, a mim me honrais,

Gabando-vos a vós, e eu fico um Rei.

Nesta vida um soneto já ditei,

Se desta agora escapo, nunca mais;

Louvado seja Deus, que o acabei. 
Releitura (cont. p. 38)

3. Segundo a rubrica, um conde pedira que Gregório de Matos lhe dedicasse um soneto de louvor (naquela época era comum os poetas escreverem poemas laudatórios em homenagem aos nobres). Explique como o poeta realizou a encomenda.

4. Faça a escansão dos seguintes versos dos poemas:

a) "14 tortuosas linhas, 13"

b) "Um soneto começa em vosso gabo"

5. Utilizando letras, faça o esquema de rimas do soneto de Gregório de Matos (em ordem alfabética, atribua uma letra a cada rima.)

Fonte: AMARAL, 2013.

A discussão de gêneros textuais, bem como seus usos, está bem difundida nos campo da linguística e educacional, neste último, principalmente no que diz respeito ao ensino de línguas (materna e estrangeira). Esse debate, todavia, ganha contornos distintos que vão, por um lado, a partir de Bakhtin (2000; 2006) e estudiosos do autor como Brait (2012), Brait e Pistori (2012) e, por outro, de Bronckart (2009; 2012) e Schneuwly e Dolz (1999; 2004). No caso de Bronckart, Schneuwly e Dolz, percebe-se uma versão dos gêneros adaptada à escola e ao ensino. Trata-se de discussão cara aos linguistas, professores e pesquisadores que abordam essa questão voltada, sobretudo, às metodologias de ensino de línguas, pois pode-se chamar de uma didatização dos gêneros. Além deles, é possível citar outros debates teóricos, como os empreendidos por Marcuschi (2008), Roxane Rojo (2004; 2008), entre outros.

Ao analisar os volumes dos livros didáticos em questão, notou-se que a discussão sobre gênero é fundamental para o ensino de literatura e exige a retomada de conceitos consagrados historicamente sobre a temática, além de encampar debates realizados a partir de Bakhtin, Schneuwly e Dolz e seus divulgadores, por exemplo.

Ao analisar o corpus desta pesquisa, livros didáticos, como espaço que permite a mobilização de saberes pertencentes tanto ao campo educacional quanto ao campo das Letras, foi preciso considerar a história do ensino de língua portuguesa, especificamente de literatura, para melhor situar a discussão dos gêneros. O percurso histórico deste ensino mantém a memória de uma metodologia pautada nesta história da literatura, bem como das escolas literárias e, ao mesmo tempo, abre espaço para abordagens dos gêneros feitas a partir das contribuições da Linguística, da Linguística Aplicada e de seus impactos no campo da Educação. Dessa forma, pode-se dizer que esse espaço do corpus vem marcado pela coexistência de abordagens. 
Sendo assim, faz-se premente resgatar as definições clássicas e as mais atuais de gêneros. Para Aristóteles, em Arte Poética (2001), dividem-se a estrutura e o conteúdo literários em três gêneros: dramático, épico e lírico. O gênero dramático retrata relações conflituosas e embates da vida, podendo ser representado por uma comédia ou uma tragédia; o gênero épico possui como característica a temática histórica, podendo apresentar-se em forma de narrativa e sendo possível mostrar em conjunto acontecimentos simultâneos (2001, p. 39); por fim, o gênero lírico possui caráter emocional, expondo a subjetividade do autor e a presença do "eu lírico".

Ao falar de gêneros, é impossível não mencionar Bakhtin, cuja contribuição é grande para os estudos da linguagem, tanto no que se refere aos campos da Linguística como ao da Literatura. $\mathrm{O}$ autor contribui para se pensarem ou se planejarem passos fundamentais no âmbito da linguagem: sua definição de signo como espaço que condiciona a linguagem como motriz na luta de classes ou, em outras palavras, a partir da palavra, signo neutro, o sujeito posicionase de acordo com o lugar em que ele está e os interesses que ele defende na arena social. Até o momento, as referências recaem sobre sua obra clássica, Marxismo e Filosofia da Linguagem (1979).

Com o objetivo de continuar a falar mais um pouco sobre gênero, recorre-se a outra obra de Bakhtin, Estética da Criação Verbal (2000), em que a definição de gênero coloca é exposta e pode trazer elementos fundamentais para esta discussão. O importante a assinalar é como a questão do gênero se apresenta e quais suas implicações para o ensino de literatura. Dessa forma, tem-se a questão dos gêneros primários, em que se encontram formas "simples" e "espontâneas" da apropriação da linguagem. De acordo com as palavras de Bakhtin, têm-se "os gêneros primários (simples) de todas as espécies, que se constituíram em circunstâncias de uma comunicação verbal espontânea” (BAKHTIN, 2000, p. 281).

No tocante aos gêneros secundários, verifica-se uma apropriação dos gêneros primários por meio de uma maior elaboração do uso da linguagem, em que a complexidade desse arranjo se apresenta como característica. Nota-se esse gênero na arte em geral, incluindo a literatura, por exemplo:

Os gêneros secundários do discurso - o romance, o teatro, o discurso científico, o discurso ideológico etc. - aparecem em circunstâncias de uma comunicação cultural, mais complexa e relativamente mais evoluída, principalmente escrita: artística, científica, sociopolítica. [...] Os gêneros 
primários, ao se tornarem componentes dos gêneros secundários, transformam-se dentro destes e adquirem uma característica particular: perdem sua relação imediata com a realidade existente e com a realidade dos enunciados alheios - por exemplo, inseridas no romance, a réplica do diálogo cotidiano ou a carta, conservando sua forma e seu significado cotidiano apenas no plano do conteúdo do romance, só se integram à realidade existente através do romance considerado como um todo, ou seja, do romance concebido como fenômeno da vida literário-artística e não da vida cotidiana. (BAKHTIN, 2000, p. 281.)

Ao refletir sobre a definição de gênero trazida por Bakhtin, tem-se um elemento fundamental para o ensino e, nesse caso, para o ensino de literatura, que reside na apropriação e objetivação do uso social de uma linguagem elaborada por meio do gênero secundário, que se apropriou de uma forma mais simples e corriqueira de comunicação por meio da linguagem e, ao elaborá-la, agregou toda uma relação ora sutil, ora explícita ao espaço de uso da linguagem, fazendo que a palavra tomasse o seu lugar, deixando de ser neutra, e demarcasse uma posição social.

Ao discorrer sobre a questão dos gêneros, pode-se estabelecer uma relação com o conceito de capital cultural de Pierre Bourdieu (1998), visto que a elaboração da linguagem percebida nos gêneros secundários pode contribuir para um tipo especializado de raciocínio que mobiliza, certamente, tipos de capital cultural, como, por exemplo, o objetivado e o incorporado, possibilitando uma percepção mais sofisticada do uso da língua e da realidade social que ela representa e, constantemente, indaga. Assim, a relação entre gênero, capital cultural e ensino de literatura parece ficar mais clara, ampliando a importância da obra didática nessa relação.

O ensino de literatura apresenta como desafio o fato, portanto, de não se restringir a dados periféricos ou, simplesmente, estruturais para situar a linguagem apropriada no interior de um jogo de forças e de poder mais complexos que é a sociedade. Essa engrenagem da língua alocada no LD parece necessitar de uma habilidade no seu tratamento didático e pedagógico para que venha à tona o sentido potente da literatura. Para tanto, a clareza sobre a questão dos gêneros e sua inerente relação com usos e posicionamentos sociais, por meio da linguagem, configura grande oportunidade e compreensão do objeto literário.

Como exemplo das possibilidades da utilização dos gêneros para o ensino de literatura e, ao mesmo tempo, seu status, Ceia (2016) apresenta uma perspectiva crítica e distinta ao defender que o gênero na literatura não é mais estático, mas, sim, passível de constante transformação, hibridizando-se ao longo dos anos. Assim, tem-se, em suas palavras: 
Desde a Poética de Aristóteles, o gênero na teoria literária tem sido usado um tanto informalmente, assim negligenciando o elemento de criatividade que se encontra por trás da tradição crítica ocidental nos estudos literários. O romance contemporâneo tem nos ensinado, precisamente, que a criatividade rompe todas as barreiras para um gênero "fixo" ou um modelo predeterminado. (CEIA, 2016, p. 3, tradução nossa.) $)^{1}$

Desse modo, a discussão acerca dos gêneros literários torna-se cada vez mais complexa, posto que o passar dos séculos e a criatividade dos autores têm modificado, cada vez mais, a categorização desses gêneros.

Novamente, nós (escritores e leitores) estamos experienciando um momento em que a literatura não consegue sustentar um status de não comprometimento com a sua natureza. Todas as formas de literatura podem ser classificadas, mesmo quando a classificação parece ser irrelevante. O que claramente contribui para esse paradoxo é a queda moderna de todas as barreiras e convenções para ser possível escrever um romance, um poema ou uma peça. (CEIA, 2016, p. 7, tradução nossa. $)^{2}$

A literatura é impactada frequentemente, uma vez que dialoga diretamente com as mudanças sociais e culturais, rompimentos e ressignificações que são realizados pelo objeto artístico, sempre com o intuito obstinado de refratar as movimentações da sociedade e da cultura de que ela faz parte. As mudanças da literatura podem ocorrer tanto no plano da narrativa, da escrita, quanto das escolhas temáticas que servem como pontos de problematização, que podem provocar um diálogo profundo e denso com o leitor. Trata-se de instância provocadora e, ao mesmo tempo, esclarecedora do tempo e do espaço.

Compreender essa complexidade da classificação dos gêneros literários na contemporaneidade é fundamental para o ensino de literatura, posto que esse olhar mais qualificado assinala maior receptividade para a discussão que envolve o ensino de língua e também de literatura.

\footnotetext{
1 "Ever since Aristotle's Poetics, in literary theory genre has been used rather informally thus disregarding the element of creativity that lays behind the Western critical tradition in literary studies. The contemporary novel has taught us, precisely, that creativity opens all boundaries to a "fixed" genre or a pre-determined model".

2 "Again, we (writers and readers) are experiencing a time where literature cannot sustain a non-compromise status with its nature. All forms of literature can be classified, even when classification seems to be pointless. What clearly contributes to this paradox is the modern fall of all boundaries and conventions for being able to write a novel, a poem or a play."
} 
No levantamento de excertos literários e de textos integrais nos livros didáticos (Ensino Médio), cabe assinalar que a presença do gênero lírico prevalece em relação ao épico e ao dramático. Com isso, foi possível mapear as inserções literárias em Novas Palavras (2013) e Português: Linguagens (2013) e nas comandas para o ensino de literatura, referentes aos excertos literários e aos textos literários na íntegra.

Além da poesia, do conto, do drama, da crônica e do romance, encontraram-se outras modalidades textuais, consideradas por estudiosos da Linguística, da Linguística Aplicada e da Educação, a partir dos estudos de Bakhtin, Bronckart, Dolz, Marcuschi, Rojo, Schneuwly, como já citados, gêneros discursivos e textuais; são cartas, cartoons, memórias e sermões.

Dessa forma, têm-se as seguintes ocorrências, mostradas na Tabela 1.

Tabela 1 - Ocorrências: gêneros presentes nos livros didáticos.

\begin{tabular}{l|c|c}
\hline & Novas Palavras & Português: Linguagens \\
\hline Poesia & 66 & 59 \\
\hline Conto & 2 & 0 \\
\hline Memória & 1 & 0 \\
\hline Drama & 4 & 1 \\
\hline Crônica & 1 & 1 \\
\hline Carta & 3 & 4 \\
\hline Cartoon & 1 & 2 \\
\hline Tratado & 1 & 0 \\
\hline Sermão & 4 & 0 \\
\hline Romance & 1 & 2 \\
\hline
\end{tabular}

Fonte: AMARAL; CEREJA, MAGALHÃES, 2013.

No intuito de visualizar melhor como a noção de ensino de literatura se apresenta nos livros didáticos, arrolam-se, na Tabela 2, as ocorrências de excertos e textos literários na íntegra, bem como comandas para o ensino de literatura: 
Tabela 2 - Ocorrências: textos literários na íntegra, excertos literários e comandas para o ensino de literatura nos livros didáticos.

\begin{tabular}{l|c|c}
\hline & Novas Palavras & Português: Linguagens \\
\hline Textos literários na íntegra & 45 & 31 \\
\hline Excertos literários & 39 & 38 \\
\hline Comandas para o ensino de literatura & 216 & 97 \\
\hline
\end{tabular}

Fonte: AMARAL; CEREJA, MAGALHÃES, 2013.

Percebe-se diferença das ocorrências de excertos e de textos literários na íntegra e de comandas para o ensino de literatura entre os dois livros analisados. Com isso, tem-se a impressão de que uma obra didática considerou importante e relevante uma abordagem mais presente do trabalho com a literatura do que a outra. Em Novas Palavras (2013), por exemplo, apresentam-se mais textos literários na íntegra, 45 inserções, do que em Português: Linguagens (2013), que conta com 31 ocorrências; quanto às comandas para o ensino de literatura, o primeiro apresenta 216, enquanto o segundo traz 97.

Cabe dizer que as comandas, referentes aos conteúdos literários, partiam de uma concepção de ensino de literatura pautada nas escolas literárias, trazendo, de forma clara e didatizada, e de acordo com uma típica organização nesses tipos de obra, os períodos literários: Trovadorismo (cantigas de amor e de amigo), Humanismo (fragmentos de autos de Gil Vicente), Barroco (os clássicos poemas de Gregório de Matos).

\section{As tendências pedagógicas e literárias do ensino de Literatura}

Após o levantamento de excertos e textos na íntegra, partiu-se para a análise desse conteúdo, a fim de situar tendências pedagógicas e literárias. A análise e a categorização dessas tendências encontradas deram-se a partir do levantamento de pronomes e advérbios interrogativos empregados nas comandas de ensino referentes aos excertos e textos literários na íntegra, como se vê na Tabela 3. 
PAYÃO, G. T.; ANNIBAL, S. F.

Tabela 3 - Descritores/impulsionadores de ação nas comandas para o ensino de literatura dos livros didáticos.

\begin{tabular}{|c|c|c|}
\hline & Novas Palavras & Português: Linguagens \\
\hline Explique & 46 & 3 \\
\hline Reescreva & 4 & - \\
\hline Leia & 31 & 8 \\
\hline Releia & 25 & 2 \\
\hline Faça a escansão & 3 & 3 \\
\hline Justifique & 7 & 9 \\
\hline Indique & 6 & 2 \\
\hline Reinterprete & - & - \\
\hline Identifique & 11 & 16 \\
\hline Observe & 7 & 7 \\
\hline Qual é*** & 35 & 24 \\
\hline Quais são*** & 6 & 5 \\
\hline Escreva & 11 & 1 \\
\hline O que é & 3 & 4 \\
\hline O que são & 1 & - \\
\hline Por que & 17 & 9 \\
\hline Por quê & 10 & 11 \\
\hline Na sua opinião & 4 & 3 \\
\hline Esquematize & 1 & - \\
\hline Defina & - & - \\
\hline Resuma & 2 & - \\
\hline Assinale & 2 & - \\
\hline Compare & 7 & 14 \\
\hline
\end{tabular}

Fonte: AMARAL; CEREJA, MAGALHÃES, 2013.

Assim, por meio desse levantamento, foram considerados os três descritores mais recorrentes em cada uma das coleções. Nota-se, no livro da coleção Novas Palavras (2013), a predominância dos verbos explicar e ler no imperativo - "Explique" e "Leia" -, o primeiro com 46 ocorrências e o segundo com 31; seguido do pronome interrogativo "qual" acrescido do verbo "ser", resultando em "Qual é”, que aparece 35 vezes.

Outro aspecto a ser observado é a transitividade direta dos verbos. Pelas comandas, temse a ideia de que o aluno deve responder a essas questões, especificamente, como foi solicitado pelo enunciado, sem, necessariamente, uma imersão maior no texto literário. Destaca-se, também, a recorrência dos verbos "Leia" e "Releia", que podem conduzir o aluno a retornar ao texto, ainda que apenas superficialmente. O que parece é que a leitura literária, consideradas suas especificidades, cede espaço a uma interpretação textual sem a preocupação com as particularidades inerentes ao campo literário.

Essa utilização verbal continuamente no imperativo ou a utilização de advérbios e pronomes interrogativos pode demandar uma resposta quase sempre objetiva e direcionada. No 
caso do ensino da literatura, isso parece uma contradição, uma vez que, mesmo ao solicitar uma intervenção livre e criativa do aluno, não há uma ambientação no enunciado dessas comandas que o convide a se posicionar no texto como integrante de um espaço e de um tempo social e cultural e, sobretudo, de sua interlocução individual e subjetiva com o objeto literário. Assim, tudo parece guiado pelo imperativo dos verbos e pela resposta estimulada e esperada pelos pronomes e advérbios.

É importante observar que, por mais que se busque uma interação mais efetiva com o estudante, os livros apresentam um diálogo com uma forma textual comum e compartilhada com demais obras didáticas da mesma natureza, pois há um formato desses tipos de obra já consagrado.

Dessa forma, apresentam-se comandas para o ensino de literatura que ilustram a discussão que vem sendo realizada neste artigo (Quadro 4).

Quadro 4 - Texto literário na íntegra no livro Novas Palavras (2013).

Novas Palavras

Capítulo 3, página 41

Poesia

Da sóror mystica, Dora Ferreira da Silva, Poesia reunida. Rio de Janeiro: TopBooks, 1999. p. 52

Donzela sem espelho atenta ao seu tear, bordando pelo avesso dragão de irado olhar. A pétala e o donzel de leve suspirar, falcão preso à corrente, pavão a cintilar. Bordando pelo avesso o escuro parecer. $\mathrm{O}$ mal torna-se bem, a terra em florescer. A cor e seu contorno se encontram de repente e o olhar que nada vê só vê o que presente. Se fosse o mundo só a fria geometria, tão certa não seria a exata fantasia. Não fosse o desamor a mágoa que persiste, do amor não nasceria a bela face triste. Donzela que tão só teces o adivinhar, recria pelo avesso o pranto e o esperar. Partiu o cavaleiro em guerras a guerrear, tua mão traçando a prata recrie o seu voltar.

Fonte: AMARAL, 2013. 
PAYÃO, G. T.; ANNIBAL, S. F.

Quadro 5 - Textos literários na íntegra e comandas para o ensino de literatura da coleção Novas Palavras (2013).

Novas Palavras

Capítulo 3, página 43

Poesia

Cantiga, de Estevam Coelho. In: VIEIRA, Yara Frateschi. Poesia medieval: literatura portuguesa. São Paulo: Global, 1987. p. 133

Sedia la fremosa seu sirgo torcendo, sa voz manselinha fremoso dizendo cantigas d'amigo.

Sedia la fremosa seu sirgo lavrando, sa voz manselinha fremoso cantando cantigas d'amigo.

- Par Deus de cruz, dona, sei eu que havedes amor mui coitado, que tam bem dizedes cantigas d'amigo.

Par Deus de cruz, dona, sei [eu] que andades d'amor mui coitada, que tam bem cantades cantigas d'amigo.

- Avuitor comestes, que adevinhades!

Paráfrase da Cantiga, Cleonice Berardinelli. Cantigas de trovadores medievais em português moderno. Rio de Janeiro: Organização Simões. 1953. p. 58-59.

Estava a formosa seu fio torcendo,

Sua voz harmoniosa, suave dizendo

Cantigas de amigo.

Estava a formosa sentada, bordando,

Sua voz harmoniosa, suave cantando

Cantigas de amigo.

Por Jesus, senhora, vejo que sofreis

De amor infeliz, pois tão bem dizeis

Cantigas de amigo.

Por Jesus, senhora, eu vejo que andais

Com penas de amor, pois tão bem cantais

Cantigas de amigo.

Abutre comeste, pois que adivinhais.

Releitura (p. 43 e 44)

1. Compare a cantiga de Estevam Coelho com o poema de Dora Ferreira da Silva e explique a semelhança entre as cenas apresentadas pelas duas composições poéticas.

2. Havia dois tipos de composição lírico-amorosa na poesia galego-portuguesa, que você estudará neste capítulo: as cantigas de amor e as de amigo. A cantiga de Estevam Coelho pertence ao segundo tipo.

a) Considerando os comentários feitos pelo observador que fala na terceira e na quarta estrofes, qual deve ser o tema frequente das cantigas de amigo? Explique.

b) Interprete a resposta dada pela moça a este observador na última estrofe. 
3. A repetição é um dos procedimentos expressivos da poesia e da música popular. Nessa cantiga, os versos são repetidos com pequenas variações, e cada estrofe termina com o refrão.

a) Faça um esquema atribuindo a cada verso original uma letra maiúscula; a cada repetição, a mesma letra em forma minúscula; ao refrão, a letra $\mathrm{R}$.

b) Procure lembrar-se de uma cantiga folclórica ou de uma música popular feita com repetições e refrão e anotea em seu caderno. Depois, leia-a em voz alta fazendo as pausas de acordo com a sintaxe e o sentido. Na sua opinião, qual é a importância do refrão nessas cantigas?

Fonte: AMARAL, 2013.

No Quadro 5 há um texto literário na íntegra, uma cantiga medieval, escrita por Estevam Coelho, e uma paráfrase dessa cantiga, escrita por Cleonice Berardinelli em 1953. Após a apresentação do texto literário e da paráfrase, a primeira comanda pede para que o aluno explique as semelhanças entre a cantiga e o texto de Dora Ferreira da Silva, que aparece na Tabela 4, em que se seleciona o referido texto da autora.

Em "Compare a cantiga de Estevam Coelho com o poema de Dora Ferreira da Silva e explique a semelhança entre as cenas apresentadas pelas duas composições poéticas", o verbo "explicar" no imperativo busca coordenar uma ação do aluno/leitor no sentido de comparar “cenas" nos dois textos, entretanto tem-se a impressão de uma informação vaga, a partir do momento de que não se deixa claro quais cenas são essas. Por um lado, permite uma liberdade desse aluno/leitor em destacar as cenas que lhe ocorrem; por outro, pode causar dúvidas em relação a quais cenas o enunciado se refere, uma vez que não se observa contextualização verbal e expressa no livro nesse sentido. Outro ponto importante e muito positivo é que a comanda leva a mais uma leitura dos textos para que o sentido do verbo “explicar" seja atingido.

A primeira parte da segunda comanda, "Considerando os comentários feitos pelo observador que fala na terceira e na quarta estrofes, qual deve ser o tema frequente das cantigas de amigo? Explique.", leva o aluno a refletir e explicar um conceito teórico, o que necessita de abordagem prévia: o tema frequente das cantigas de amigo e das cantigas de amor. Esse exercício propõe que o aluno retorne ao texto e analise as características expostas pelos poetas em determinadas estrofes; esse retorno é positivo, pois conduz a uma nova leitura dos textos literários. A segunda parte da comanda, "Interprete a resposta dada pela moça a este observador na última estrofe", leva o aluno a se posicionar em relação ao texto, o que direciona que ele volte, mais uma vez, à cantiga.

A presença dos verbos “explicar" e "interpretar" no imperativo está relacionada com o ensino de literatura, tendo em vista que esses verbos apresentam-se dessa maneira nos livros 
didáticos. Se faz importante, por um lado, refletir o posicionamento docente no que diz respeito ao ensino e, por outro, a mobilização de práticas de aprendizagem, que podem surtir efeitos positivos na relação do aluno com o objeto literário. Além disso, é preciso reforçar a importância da centralidade desse objeto literário, pois, se não for abordada e discutida, a utilização, sem a contextualização e a problematização, dos verbos "explicar" e "interpretar" pode induzir a uma análise do texto literário que o distancia de suas características literárias e estéticas.

Pontua-se, ainda, a ligação entre o aluno/leitor e a cultura que produziu esses textos literários, de modo que é significativo compreender como ele efetiva o ato de ler. Sendo assim, os verbos no imperativo que aparecem nas comandas de ensino podem induzir o leitor a voltar ao texto, contudo a aproximação do texto literário guiada por essas comandas muitas vezes abordam características textuais que não propiciam uma investida contundente nos aspectos estéticos e literários dos excertos ou dos textos. Não se pretende dizer que a literatura não é abordada; o que se observa é a importância de uma discussão proporcionada pelo ensino e pela aprendizagem sobre a literatura em si, sem utilizá-la como possibilidade de ensino de gramática ou como exercício de interpretação de texto.

Reforça-se que o emprego dos verbos "explicar" e "interpretar" no imperativo fazem parte de uma dinâmica, lógica ou, ainda, uma prática que permanece nos diferentes livros didáticos, cuja estrutura de comandas de ensino não passou por mudanças significativas ao longo do tempo, obedecendo à referida dinâmica ou lógica.

Na terceira comanda, orienta-se o aluno a ler, em voz alta, uma cantiga folclórica ou uma música popular feita com repetições e refrão que ele conheça, fazendo pausas de acordo com sintaxe e sentido; depois, questiona-se: "Na sua opinião, qual é a importância do refrão nessas cantigas?". "Na sua opinião", impulsionador que, semanticamente, distancia-se de uma ordem e convida o aluno/leitor a se posicionar e a opinar sobre a construção do texto literário, aparece apenas quatro vezes no volume, enquanto o emprego do imperativo aparece em uma frequência numericamente superior. Nota-se uma tentativa de romper com o uso do imperativo, ao ceder espaço de voz ao aluno/leitor, proporcionando que ele exponha seu posicionamento em relação ao texto literário. Reitera-se, neste momento, o papel do professor, que é fundamental na permanência ou na ruptura com as tendências tecnicista e tradicional, que serão mais bem esclarecidas mais adiante.

Trata-se de um discurso pedagógico que, ao não ser desconstruído ou problematizado, 
pode fazer a manutenção dessas tendências, uma vez que o fato de mudar a lógica semântica de ordenar para solicitar a opinião do aluno/leitor pode significar pouca coisa sem a interferência do docente; por isso assinala-se a importância de um tipo de formação de professores que vislumbre a reflexão e, se necessário, a problematização do discurso pedagógico impresso nos livros didáticos ou em qualquer outro veículo de comunicação com a escola.

No LD da coleção Português: Linguagens (2013), nota-se predominância do pronome interrogativo seguido do verbo ser, "Qual é", com 24 ocorrências, além dos verbos identificar e comparar no imperativo: "Identifique", com 16 ocorrências, e "Compare", que aparece 14 vezes. Por várias vezes, tanto excertos como textos literários na íntegra aparecem agrupados ao longo das seções da obra didática, de modo que quatro ou cinco excertos ou textos integrais se relacionam para a realização de várias comandas de ensino de literatura. Logo, entende-se o uso, por exemplo, do verbo comparar, como vê-se no Quadro 6.

Quadro 6 - Texto literário na íntegra e comandas para o ensino de literatura da coleção Português: Linguagens (2013).

Português: Linguagens

Capítulo 7, unidade 3; páginas 285-6.

Poesia

Ofendi-vos, Meu Deus, bem é verdade. Gregório de Matos. In: Antologia da poesia barroca brasileira, cit. p. 45 .

Ofendi-vos, Meu Deus, bem é verdade,

É verdade, meu Deus, que hei delinqüido,

Delinqüido vos tenho, e ofendido,

Ofendido vos tem minha maldade.

Maldade, que encaminha à vaidade,

Vaidade, que todo me há vencido;

Vencido quero ver-me, e arrependido,

Arrependido a tanta enormidade.

Arrependido estou de coração,

De coração vos busco, dai-me os braços,

Abraços, que me rendem vossa luz.

Luz, que claro me mostra a salvação,

A salvação pertendo em tais abraços,

Misericórdia, Amor, Jesus, Jesus.

1. No texto, o eu lírico dirige-se diretamente a Cristo, falando de si mesmo.

a) Como o eu lírico se coloca diante de Cristo?

b) Na primeira estrofe, o eu lírico faz um jogo com dois verbos que revelam seu pecado. Quais são os verbos?

c) Que característica pessoal o eu lírico apresenta como causa do seu pecado? 
2. Na segunda estrofe, o eu lírico continua sua confissão.

a) Ele se confessa "vencido" e diz que quer "ver-se vencido". Quais são os agentes dessas duas expressões?

b) Que palavra dessa estrofe constitui uma antítese em relação a delinquido ou ofendido?

3. Levando em conta a presença do vocativo "meu Deus", do imperativo "dai-me" e da declaração devocional do último verso, a que gênero textual se assemelha o poema?

4. Leia, a seguir dois tercetos da lírica religiosa de Gregório de Matos, nos quais o eu lírico também se dirige a Cristo pedindo salvação.

Eu sou, Senhor, a ovelha desgarrada,

Cobrai-a; e não queirais, pastor divido,

Perder na vossa ovelha a vossa glória.

(In: Antologia da poesia barroca brasileira. cit, p. 47)

Mui grande é o vosso amor, e meu delito,

Porém pode ter fim todo o pecar,

E não o vosso amor, que é infinito.

(In: Idem, p. 46)

O eu lírico busca a sua salvação por meio da argumentação.

a) De que argumentos ele lança mão no primeiro fragmento?

b) E no segundo fragmento?

5. No soneto em estudo, é empregada uma figura de linguagem chamada anadiplose, que consiste em um encadeamento de palavras feito de modo que um termo empregado no final de um verso dá início ao verso seguinte. Qual é a importância desse recurso para a argumentação que o eu lírico faz junto a Cristo?

6. Com base no que aprendeu até aqui acerca da linguagem barroca, você diria que o texto é cultista ou conceptista?

Fonte: CEREJA; MAGALHÃES, 2013.

O Quadro 6 conta com um texto literário na íntegra, um soneto escrito por Gregório de Matos e seis comandas de ensino de literatura sobre esse texto; nota-se uma diferença no formato de apresentação das comandas neste volume do LD, isto é, na maioria dos capítulos há o agrupamento de mais de um excerto ou texto literário na íntegra relacionados com um conjunto de comandas de ensino. Nesse caso, contudo, o texto literário surge, isoladamente, fora do agrupamento e contém diferentes comandas sobre o soneto de Gregório de Matos.

Essas comandas promovem uma ideia de ensino e, consequentemente, pretendem atingir as práticas de aprendizagem no que diz respeito ao olhar do aluno/leitor sobre características formais do texto até uma aproximação de seu sentido estético e literário, resvalando, algumas vezes, em aspectos de enquadramento em gêneros. Talvez a quebra de formato na apresentação isolada do soneto se dê pelo fato de se tratar do gênero poesia, pois esse gênero permite a utilização integral no espaço gráfico e editorial do LD. 
A primeira comanda divide-se em três partes: "Como o eu lírico se coloca diante de Cristo?", "Na primeira estrofe, o eu lírico faz um jogo com dois verbos que revelam seu pecado. Quais são os verbos?" e "Que característica pessoal o eu lírico apresenta como causa do seu pecado?". Assinala-se, aqui, a atenção para os aspectos formais do texto literário, partindo da identificação da postura do eu lírico, seguida pela identificação de verbos no soneto e, por fim, situando a causa do pecado do eu lírico.

A segunda comanda dá continuidade a essa reflexão, questionando quais os agentes das expressões "vencido" e "ver-se vencido", além de indagar qual palavra da referida estrofe constitui uma antítese para delinquido ou ofendido. As questões envolvem grande complexidade, posto que é necessário que o aluno compreenda não só aspectos da interpretação textual, como também questões estilísticas acerca do texto literário.

A terceira comanda busca dialogar com a questão do gênero textual ao indagar: “Levando em conta a presença do vocativo 'meu Deus', do imperativo 'dai-me' e da declaração devocional do último verso, a que gênero textual se assemelha o poema?”.

O LD apresenta, na quarta comanda, mais dois tercetos de Gregório de Matos, questionando quais os argumentos utilizados pelo autor nesses dois casos específicos. Pontuase que, nas comandas, utiliza-se a palavra "excerto", e não "terceto", o que, a depender da apresentação da obra literária, certamente mobilizaria mais vocabulário e, consequentemente, maior conhecimento do campo literário, preparando o aluno/leitor para novas experiências com a literatura.

A quinta comanda retorna ao soneto em estudo e também às argumentações, pontuando a anadiplose como figura de linguagem utilizada por Gregório de Matos como recurso, além de questionar "Qual é a importância desse recurso para a argumentação que o eu lírico faz junto a Cristo?’. Essa e a sexta comanda, que questiona o aluno/leitor acerca de estilos próprios da estética barroca, reforçam uma abordagem dos aspectos formais do texto literário que são explorados ao longo das comandas apresentadas pelo LD.

É possível perceber, na estruturação das comandas de ensino relacionadas com o texto poético, por exemplo, um formato que dialoga com a tendência tecnicista (LIBÂNEO, 1985), de modo que se sente a falta de um aprofundamento do texto literário, isto é, de suas questões estéticas e, intrinsecamente, literárias; deixa-se claro que essa investida no texto literário poderia ser feita a partir de qualquer abordagem crítica ou teórica, seja pelo viés sociológico, seja pelo viés fenomenológico, entre outros. 
Não se observa contudo, qualquer investida no sentido de aprofundamento no conteúdo literário; nota-se, portanto, uma ênfase nos aspectos formais do texto, ou seja, o indicativo de análise feito pelas comandas de ensino do LD mantém-se na superfície da análise e atém-se em argumentos, análises sintáticas, figuras de linguagem e características ortodoxas e consagradas pela dinâmica editorial e escolar das escolas literárias.

Dessa forma, recorre-se às palavras de Libâneo (1985) para trazer à tona o conceito de uma tendência tecnicista:

\begin{abstract}
As etapas básicas de um processo [tecnicista] de ensino-aprendizagem são: a) estabelecimento de comportamentos terminais, através de objetivos instrucionais; b) análise da tarefa de aprendizagem, a fim de ordenar sequencialmente os passos da instrução; c) executar o programa, reforçando gradualmente as respostas corretas correspondentes aos objetivos. O essencial da tecnologia educacional é a programação de passos sequenciais empregada na instrução programada, nas técnicas de microensino, multimeios, módulos etc. (p. 31)
\end{abstract}

No intuito de discutir mais um pouco essa questão das tendências pedagógicas e relacioná-las com o tema que vem sendo desenvolvido neste texto, pode-se pensar, além da tendência tecnicista explanada por Libâneo (1985), em uma abordagem tradicional que, segundo Mizukami (1986):

[...] é um ensino caracterizado por se preocupar mais com a variedade e quantidade de noções/conceitos/informações que com a formação do pensamento reflexivo. Ao cuidar e enfatizar a correção, a beleza, o formalismo, acaba reduzindo o valor dos dados sensíveis ou intuitivos, o que pode ter como consequência a redução do ensino a um processo de impressão, a uma pura receptividade (p. 14).

Sendo assim, percebe-se uma relação com a abordagem tradicional no ensino de literatura em Novas Palavras (2013) e Português: Linguagens (2013), uma vez que conceitos referentes às escolas literárias, às noções de interpretação textual e às informações acerca do período literário se apresentam, o que pode reduzir o acesso a uma imersão no fenômeno literário. Corre-se o risco de não haver um aprofundamento dos aspectos literários do texto.

Torna-se possível discutir aspectos referentes à permanência de diálogos com tendências tecnicista e tradicional no tratamento do conteúdo literário e nas comandas de ensino que os acompanham. Dessa forma, destaca-se que não é intenção generalizar e estender essa 
afirmação à obra didática como um todo, mas apenas aos volumes analisados, o que torna representativo um olhar que ainda permanece sobre o ensino de literatura.

No tocante às tendências literárias, recorre-se a Eagleton (2006), que contribui para esta discussão no momento em que é possível se obter clareza de uma relação mais concreta entre a forma de conduzir o ensino e, consequentemente, o acesso às construções de conceitos, e a maneira de olhar, abordar ou, ainda, tratar o texto literário.

É possível, também, pensar em uma correspondência entre os aspectos de tendências tecnicista e tradicional com um tratamento literário pautado no estruturalismo; nesse caso, a leitura circunscreve-se à estrutura e parece tornar-se difícil o adentramento pelas camadas do texto que levariam o leitor literário a identificar elementos que lhe permitiriam compreender a cultura que o cerca de forma a transcender o senso comum: função da obra literária.

Em relação ao estruturalismo, Eagleton discorre sobre a análise de poema, que parece ser fundamental para entender como esse tipo de olhar analítico se constrói no objeto literário:

\begin{abstract}
Podemos examinar um poema como uma "estrutura" e, ao mesmo tempo, tratarmos cada um de seus itens como mais ou menos significativos em si mesmos. Pode ser que o poema encerre uma imagem sobre o sol e outra sobre a lua, e pode ser que estejamos interessados em ver como essas duas imagens se combinam para formar uma estrutura. Mas só nos tornamos estruturalistas convictos quando pretendemos que o significado de cada imagem só existe em relação à outras imagens. (EAGLETON, 2006, p. 143.)
\end{abstract}

As comandas de ensino de literatura do LD surgem envoltas nas estruturas do texto literário; não se quer dizer que não seja necessário conhecer essas estruturas, no entanto essa aproximação não pode restringir-se à identificação, mas ultrapassar esse formato no sentido de uma apropriação mais efetiva da obra literária. $\mathrm{O}$ estruturalismo não pode ser visto apenas como sinônimo de mapeamento de uma estrutura, e esse discernimento está relacionado com a formação do docente que conduz, no espaço escolar, o diálogo com a literatura. Por outro lado, nota-se uma tentativa de rompimento da obra didática com esse viés tecnicista e tradicional em diálogo com o estruturalismo no momento que se percebe uma aproximação com a abordagem por meio dos gêneros, mesmo que em uma perspectiva somente textual.

O livro didático Português: Linguagens (2013) segue o formato editorial de qualquer outro LD, no entanto, ao se observarem com mais atenção as referências, percebe-se um aporte teórico no que diz respeito ao ensino de língua portuguesa, lançando mão de uma bibliografia 
atualizada e crítica desse ensino, como se pode ver em Bagno (2007) e Rojo (2000), Marcushi (2008) e Possenti (2011), por exemplo. Vê-se, na presença dessas referências para o ensino da língua portuguesa, uma preocupação em situar questões de linguagem e de gêneros textuais e discursivos, lembrando que, ao falar de gênero, tem-se, ainda, sua vertente didatizada por meio de autores como Schneuly e Dolz (1999).

Quanto ao aporte teórico referente à teoria literária, nota-se a permanência de um paradigma que privilegia a teoria e a crítica literária, como é possível perceber-se pela utilização de autores como Bosi (1972), Candido (1975) e Lapa (1942). Destaca-se a quase ausência de bibliografia especializada no ensino da literatura, discussão que se encontra em voga desde os anos 1960 até os dias atuais em diferentes perspectivas, a exemplo de Leite (1983), Colomer (2003), Rezende (2013), entre outros.

Ao atentar-se às comandas de ensino, percebe-se, no que diz respeito ao ensino da língua, uma tentativa de alinhamento às discussões mais críticas e atualizadas por meio de uma conscientização e usos dos gêneros discursivos ou textuais, por exemplo. Já no que concerne ao ensino da literatura, assinala-se a permanência de um viés da história da literatura expresso pela utilização de excertos de obras literárias ou de alguns textos poéticos na íntegra, seguindo, portanto, uma ortodoxia editorial dos livros didáticos para o ensino do texto literário.

Além disso, reforça-se a utilização, pelos autores, na apresentação e nas referências, do sintagma "linguagem", o que pode ser entendido como tentativa de alinhamento a uma concepção atual de ensino de língua portuguesa:

Estudar a literatura portuguesa e a literatura brasileira implica conhecer sua origem, sua história e suas relações socioculturais, além das relações existentes entre elas e outras linguagens e entre elas e o mundo contemporâneo. (CEREJA; MAGALHÃES, 2013, p. 10.)

O livro didático, portanto, tem um papel importante no ensino de literatura, no Ensino Médio, justamente por mediar as relações linguísticas e culturais, bem como a complexidade do texto literário. Ao considerar os descritores/impulsionadores das comandas, que se relacionam aos excertos e textos literários na íntegra, pontua-se que as obras didáticas contam com tendências pedagógicas tradicionais e tecnicistas, seguindo um formato já consagrado pelas práticas editoriais. 


\section{Considerações finais}

As reflexões desenvolvidas neste texto foram resultado de estudo e análise de duas obras didáticas: Novas Palavras (2013) e Português: Linguagens (2013), em que se notaram a permanência de um formato já consagrado de livros didáticos e avanços na apropriação da noção de gêneros textuais, o que os alinha a uma discussão contemporânea para o ensino de línguas.

No tocante à literatura, entretanto, pontua-se a manutenção de uma forma de tratar, metodologicamente, o texto literário, ou seja, prevalece a sistematização por meio de escolas literárias e a continuidade de uma história da literatura. É importante salientar que as tentativas de ruptura vão ao encontro, justamente, das discussões de gêneros textuais. Isso se deve, talvez, a um desenvolvimento maior dos estudos sobre a aplicação dos gêneros no ensino de línguas.

Nessa perspectiva, é possível assinalar a influência da obra de Bakhtin e, também, a tendência hegemônica nesse debate a partir dos pressupostos de Dolz e Schneuwly, que desenvolvem uma discussão acerca dos gêneros, didatizando-os.

Sendo assim, percebem-se duas formas de se encararem os gêneros nos dois volumes: uma a partir das noções de gêneros textuais e discursivos e a outra, que busca manter a divisão clássica de gêneros literários, no entanto acena ou incorpora, pelas comandas de ensino de literatura, a discussão sobre gêneros levada à frente pela linguística, linguística aplicada ou pela educação quando essas discussões estabelecem diálogo com as práticas pedagógicas ou didáticas.

A análise apontou para a manutenção de um tipo de ensino de literatura que obedece a uma lógica ou ortodoxia das formas de se apresentar a literatura aos alunos por meio do livro didático, o que significa a permanência do uso de excertos literários, empregados para obras mais volumosas, normalmente narrativas, e textos na íntegra utilizados, em sua maioria, para obras poéticas.

Esses são pontos fundamentais para a discussão desenvolvida neste artigo, pois sabe-se que há uma questão editorial envolvida, o que não torna possível incorporar obras literárias na íntegra, devido, por exemplo, ao espaço gráfico destinado a esses livros.

Essa presença, no entanto, mediada por fragmentos de narrativas e poemas na íntegra, requer uma formação de professores de literatura altamente aperfeiçoada e capaz de conduzir um processo de ensino e aprendizagem da literatura menos editado e menos restrito, o que 
implica ir além ou ressignificar aspectos calcados em características estruturais ou tecnicistas do objeto literário, seja poema, seja narrativa. No caso específico da formação docente de literatura, tem-se o curso de Letras, que, portanto, necessitaria fortalecer uma articulação curricular entre as disciplinas de conhecimentos específicos e as disciplinas de conhecimentos didático-pedagógicos, uma vez que o resultado final de formação do aluno da licenciatura em Letras é o exercício da docência.

É importante dizer que se notou a presença, no que tange ao ensino de literatura nos livros didáticos, de um diálogo, por um lado, com tendências tecnicistas e tradicionais e, por outro lado, com tendências estruturalistas; todavia vê-se, com força, na apresentação dos volumes, na redação das comandas e nas referências bibliográficas, uma tentativa de alinhamento com discussões contemporâneas sobre linguagem que buscam superar esse diálogo.

Finalmente, reitera-se que essa tentativa de rompimento com essas tendências é um aspecto muito positivo dessas obras e, mais uma vez, o manuseio dos livros didáticos dependerá da formação de professores em Letras, tendo em vista que não é aconselhável que se utilize o livro como um manual de instruções, mas como uma peça didática que contribui para o processo de ensino e aprendizagem.

\section{Referências}

AMARAL, E., et al. Novas palavras: $1^{\circ}$ ano. 2. ed. São Paulo: FTD, 2013.

ARISTÓTELES. Arte Poética. Portal Domínio Público: CultVox, 2001. Disponível em: http://www.dominiopublico.gov.br/pesquisa/DetalheObraForm.do?select_action=\&co_obra=2 235. Acesso em: $11 \mathrm{dez} .2020$.

BAKHTIN, M. A estética da criação verbal. Tradução M. E. G. Pereira, São Paulo: Martins Fontes, 2000. (Original de 1979)

BAKHTIN, M.; VOLOCHINOV, V. N. Marxismo e filosofia da linguagem. São Paulo: Hucitec, 2006.

BANDEIRA, M. Noções de história das literaturas. 5. ed. Rio de Janeiro: Fundo de Cultura, 1960. $2 \mathrm{v}$.

BAGNO, M. Nada na língua é por acaso. São Paulo: Parábola, 2007.

BOSI, A. História concisa da literatura brasileira. São Paulo: Cultrix, 1978. 
BOURDIEU, P.; CHAMPAGNE, P. P. Os três estados do capital cultural. Magali de Castro (trad.). In: NOGUEIRA, M. A.; CATANI, A. M. (org.). Escritos de educação. Petrópolis, RJ: Vozes, p. 71-79, 1998.

BRAIT, B.; PISTORI, M. H. C. A produtividade do conceito de gênero em Bakhtin e o círculo. São Paulo: Revista Alfa, 2012, p. 371-401.

BRAIT, B.; SOUZA, M. C. (org.) Texto ou discurso? São Paulo: Contexto, 2012.

BRASIL. Ministério da Educação. Guia de livros didáticos. PNLD 2015: Língua portuguesa: Ensino Médio. Brasília: MEC/SEF, 2014.

BRONCKART, J. Atividades de linguagem, textos e discursos. Por um interacionismo sociodiscursivo. Trad. Anna Rachel Machado, Péricles Cunha, 2. ed. São Paulo: EDUC, 2009.

BRONCKART, J. Bakhtin desmascarado: história de um mentiroso, de uma fraude, de um delírio coletivo. Trad. Marcio Marcionilo. São Paulo: Parábola, 2012.

CAMPATO JÚNIOR, J. A. Manual de literaturas de língua portuguesa. Curitiba: CRV, 2016.

CANDIDO, A. O direito à literatura. In: CANDIDO, A. Vários escritos, v. 5, p. 171-19, 2011.

CEIA, C. Genre Categorization in Contemporary British and US-American Novels.

CLCWeb: Comparative Literature and Culture, v. 18, n. 3, p. 1, 2016.

CEREJA, W. R.; MAGAlHÃES, T. C. Português: linguagens, literatura, produção de texto e gramática. São Paulo: Editora Saraiva, 2013.

COLOMER, T. A formação do leitor literário. São Paulo: Global Editora, 2003.

DANTAS, J. M. de S. Novo manual de literatura: análise de textos literários e não literários. São Paulo: Difel, 1979.

DOURADO, A. Breve manual de estilo e romance. Belo Horizonte: Editora da UFMG, 2009.

EAGLETON, T. Teoria da Literatura: uma introdução. Trad. Waltensir Dutra; [revisão da tradução João Azenha Jr.]. 6. ed. São Paulo: Martins Fontes, 2006.

LAPA, R. Lições de literatura portuguesa. 2. ed. Coimbra: Coimbra Editora, 1942.

LEITE, L. Invasão da Catedral. 1. ed. Porto Alegre: Mercado Aberto, 1983.

LIBÂNEO, J. C. Democratização da escola pública, a pedagogia crítico-social dos conteúdos. 28. ed. São Paulo: Loyola, 2014.

LUDKE, M; ANDRE, M. A análise documental. Pesquisa em Educação: Abordagens qualitativas. 2. ed. Rio de Janeiro: EPU, 2015. 
MARCUSCHI, L. A. Produção textual, análise de gêneros e compreensão. São Paulo: Parábola, 2008.

MIZUKAMI, M. da G. N. Ensino: as abordagens do processo. São Paulo: Editora Pedagógica e Universitária, 1986.

PIRES, O. Manual de teoria e técnica literária. Rio de Janeiro: Presença, 1981.

POSSENTI, S. Questões de linguagem: Passeio gramatical dirigido. São Paulo: Parábola, 2011.

REZENDE, N. L. de. O ensino de literatura e a leitura literária. Leitura de literatura na escola. São Paulo: Parábola, p. 99-112, 2013.

ROJO, R. Gêneros do discurso e gêneros textuais: questões teóricas e aplicadas. In:

MEURER, J. L; BONINI A.; MOTTA-ROTH, D. (org.). Gêneros: teorias, métodos, debates. São Paulo: Parábola Editorial, 2005, p. 184-207.

ROJO, R. (org.). A prática de linguagem em sala de aula. São Paulo: EDUC; Campinas: Mercado de Letras, 2000.

SCHNEUWLY, B.; DOLZ, J. Os gêneros escolares - das práticas de linguagem aos objetos de ensino. Revista Brasileira de Educação. n. 11, p. 5-16, 1999.

Recebido em: $12 / 12 / 2018$

Revisado em: 29/01/2021

Aprovado em: 03/02/2021

Publicado em: 15/03/2021 